\title{
Assessment of Home-Based Nigerian Engineers on Risk Management Approach during Project Implementation
}

\author{
*AJIBOLA, OOE; OMIYALE, AD; OGUNWOLU, L
}

\author{
Department of Systems Engineering, University of Lagos, Akoka, Yaba, Lagos, Nigeria \\ Email: waleisiro@gmail.com; omiyaleabolade@yahoo.com; fogunwolu@unilag.edu.ng
} Tel.: +234(0)8034488877; +234(0)8024964333; +234(0)8033538328

\begin{abstract}
The objectives of this paper are to identify possible gaps in identification, evaluation, analysis, implementation and effectiveness of risk management approaches among home-based consulting Engineers in Nigeria vis-à-vis the implementation of such practices. Structured Questionnaire method was adopted as the survey instrument to collect data centred on issues on the subject matters. Out of 80 questionnaires distributed, 61 were returned and 6 of the returned responses rendered invalid leaving 55 valid questionnaires. The Analysis of Variance (ANOVA) and Correlation methods were adopted for statistical analysis with respect to which four hypotheses based on the subject matter were formulated and evaluated using the F-and Correlation statistics. The first premised on risk identification resulted in comparative F-statistics of $F_{c a l}=0.057592<\mathrm{F}_{\text {crit }}=2.866081$, the second on risk evaluation yielded $F_{c a l}=0.194683<\mathrm{F}_{\text {crit }}=2.866081$ while the third based on risk management implementation resulted in $F_{c a l}=$ $0.093474<\mathrm{F}_{\text {crit }}=2.866081$. The results of the first three hypothesis indicted the home-based Consulting Engineers of not identifying, analysing/evaluating and implementing risk management approaches in project execution respectively. The fourth hypothesis premised on correlation between management approach and policy implementation yielded a correlation statistics of 0.501642 establishing a positive correlation between the two among the home-based Consulting Engineers. The study thus establishes risk management practices as key to successful project management and its neglect as major causal factor for project failures in Nigeria.
\end{abstract}

DOI: https://dx.doi.org/10.4314/jasem.v22i3.3

Copyright: Copyright (C) 2018 Ajibola et al. This is an open access article distributed under the Creative Commons Attribution License (CCL), which permits unrestricted use, distribution, and reproduction in any medium, provided the original work is properly cited.

Dates: Received: 19 January 2018; Revised: 22 February: 2018; Accepted: 14 March 2018

Keywords: Risk, Uncertainty, Risk Management, Engineering Consultants, Project Managers

Timely completion of project executed within budget is regarded as a major indicator of success and efficiency in project handling. However, there are many factors that determine the successful completion of projects and these factors originate from various sources. At the commencement of any project, there are no guarantees of its success, (Omiyale, 2014). Projects can run into unexpected problems since no project is risk free. Risk may be described as the possibility that an action or activity will produce an undesired outcome or in an extreme case, lead to a loss of any kind. It refers to any uncertain event or condition that can change the outcome of a project (Holton, 2004). It is exposure to the chance of occurrences of events adversely or favourably affecting project objectives as a consequence of uncertainty (Al-Bahar et. al., 1990). Therefore, assessment and management of risk are integral components of the project management. Contemporary project risk management focuses on identifying, analysing and responding to project risks in a proactive manner.
Ramp (2000) identified three factors that characterize risk as: the risk event, its likelihood of occurrence and the impact of the risk occurrence. The ability to understand the emergence of risk, and to manage and control risk is a prerequisite for individuals, organizations, and society to survive and operate safely (Aven T., 2003). Informed risk assessment of projects is needful in order to determine its acceptability and thus continuity or termination of the project pursuance. When such assessed project has inherent level of acceptability of risk, effective risk management becomes indispensable for the project to succeed. Risk management is the process of identifying, assessing, and controlling risks arising from operational factors and making decisions that balance risk costs with mission benefits. Risk management planning is the process of deciding how to approach and conduct the risk management activities for a project (Project Management Institute (PMI), 2004, Aven T., 2003, BS IEC 2001).

The process of risk management includes the following: (1) Risk Identification, which involves 
identifying, categorizing and recording potential risks, together with information on their cause(s) and possible effect(s), which might affect the project objectives (Shehu and Sommerville 2006). (2) Risk Assessment/Evaluation, which entails evaluating the consequences associated with risks and to assess the impact of risk by using risk analysis and measurement techniques (Flanagan and Norman 1997). (3) Risk Quantification which is the analysis of potential consequences of risk and the setting of priority for ameliorating it. (4) Risk Response Development: actions or activities that are implemented to deal with specific risks or combination of risks (Osipova 2008). It draws inference on risk management to either retain a risk or transfer it to another party (Flanagan and Norman 1997) and directed at identifying a way of dealing with the identified and assessed project risks (Caltrans 2007). BS IEC (2001), PMI (2000), Smith et al. (2006), Flanagan and Norman (1997) and Vaughan (1997) identified four main negative risk response strategies as risk avoidance, risk reduction, risk transfer and risk retention. PMBOK (2004) exhaustively discussed suggested strategies for handling the negative risks which are corroborated by Baker et al. (1999), Thompson and Perry (1992) and Ibiwoye et al., (2012). PMBOK (2004), also suggested strategies for positive risks or opportunities to include: Exploit, Share and Enhance. These are also corroborated by Carter and Doherty (1974) and Flanagan and Norman (1997). Finally, the process of risk management includes (5) Risk Response Control (or Monitoring) which, according to Caltrans (2007) keeps track of the identified risks, residual risks, and new risks as well as monitors the execution of planned strategies on the identified risks and evaluates their effectiveness. Keeping risk under control involves doing four things: (a) Reviewing the risk list at every daily or weekly status meeting, (b) Keeping an eye out for trouble and constantly talking about what is going on, (c) Reducing risk through good communications and (d) Periodically reviewing the whole schedule and plan.

The objective of this paper is to assess the homebased Nigerian Engineers on Risk Management practices during project implementation.

\section{MATERIALS AND METHODS}

Data Collection Procedure: The survey instrument employed to collect data was the questionnaire method. The Questionnaire items are questions/statements based on implementation and Effectiveness of Implementation of Risk Management Approaches, risk identification, analysis and evaluation as well as relationship between risk management and Risk Policy Management implementation. The target responses on the questionnaire items centred on varied seven, five and binary response scale ratings depending on the subject matter of the item of questionnaire. The target respondents were randomly divided into five groups (A, B, C, D and E) in order to forestall bias in grouping.

A total of 80 questionnaires were distributed, 61 representing $76 \%$ of the overall sample size were returned. 6 were rendered invalid due to poor articulation of the respondents leaving 55 valid questionnaires. The academic, professional and biological profiles of respondents are as depicted in Table 1.

Table 1: Academic, Professional and Biological Profiles of the Respondents

\begin{tabular}{|c|c|c|}
\hline & & $\begin{array}{l}\text { No of } \\
\text { respondents }\end{array}$ \\
\hline \multirow{7}{*}{ Position } & Chief Executive & 5 \\
\hline & Director of Finance & 1 \\
\hline & Risk Manager/ Civil & 24 \\
\hline & Engineer & \\
\hline & Architect/Project Manager & 9 \\
\hline & Quantity Surveyor & 6 \\
\hline & Others & 10 \\
\hline \multirow{4}{*}{$\begin{array}{l}\text { Academic } \\
\text { Qualification }\end{array}$} & Ph.D. & 1 \\
\hline & M.Sc./M.Eng. & 12 \\
\hline & B.Sc. / B.Eng. & 33 \\
\hline & HND & 9 \\
\hline \multirow{3}{*}{$\begin{array}{l}\text { Professional } \\
\text { Qualification }\end{array}$} & COREN & 16 \\
\hline & MNSE & 29 \\
\hline & Any Other & 10 \\
\hline \multirow{5}{*}{$\begin{array}{l}\text { Years of } \\
\text { Practice }\end{array}$} & 1-5 Years & 6 \\
\hline & 6-10 Years & 21 \\
\hline & 11-15 Years & 20 \\
\hline & 16-20 Years & 2 \\
\hline & 20 years and above & 6 \\
\hline \multirow{4}{*}{$\begin{array}{l}\text { Area of } \\
\text { Specialization }\end{array}$} & Structure & 31 \\
\hline & Road & 9 \\
\hline & Water & 0 \\
\hline & Other & 15 \\
\hline \multirow[t]{2}{*}{ Sex } & Male & 48 \\
\hline & Female & 7 \\
\hline
\end{tabular}

Data Analysis: According to Shamoo and Resnik (2003) data analysis is the process of systematically applying statistical and/or logical techniques to describe and illustrate, condense and recap and evaluate data. Various analytic procedures provide a way of drawing inductive inferences from data, distinguishing signal of phenomenal interest from the noise (statistical fluctuations) present in the data. Data analysis is one of the crucial steps that must be completed when conducting a research experiment. It involves gathering, reviewing, and analysing data from various sources to form some sort of findings or 
conclusion. There are a variety of data analysis methods, some of which include data mining, text analytics, business intelligence, and data visualizations. Microsoft Excel software was used for the statistical analyses in this study. Descriptive statistical analysis was used in assignment of weight to responses to the questions in the questionnaire. The statistical significance of relationships among selected variables was determined using the Analysis of Variance (ANOVA). The level of significance was set at 0.05 .

Statistical Analysis: Two statistical tools were used in the analysis of the results of this survey. These are Analysis of Variance (ANOVA) and Correlation Coefficient.

\section{RESULTS AND DISCUSSION}

The major problem identified in risk management practice among home-based consultants/project managers is poor risk management policy implementation vis-à-vis identification of risk and analysis of risk which makes risk management unattractive. Results from the above show very high discrepancies in the calculated F- statistics and the Critical F-Statistics (2.808489, 2.671398 and 2.772607 representing 97.9, 93.2 and 96.1 percent discrepancies over the F-Critical value) for risk identification, risk analysis/evaluation and risk management respectively. This is an evidence that the home-based Engineers still have a long way to go in coming to terms with the enormous benefits of risk assessment and management to the success of engineering projects. This can be attributable to low level of awareness of risk management procedures among the home-based industry practitioners. This is clearly evident in the results of the analysis of the data as most of the respondents attached less importance to the practice of risk management. Consequently, implementation of risk management policies in project handling is at low ebb in practice in this locality and it is a strong indication that most of the home-based consultants / project managers do not identify and analyse project risk holistically due to low level of awareness of risk management method. This view is supported by Akintoye and Macleod (1997) who in their wisdom stated that formal risk analysis techniques are rarely used due to lack of knowledge.

The average weighted response on implementation of risk management approaches and the analysis of variance are presented in Tables 2 and 3 respectively.

Table 2: Aggregate Weighted Responses on Implementation of Risk Management Approaches

\begin{tabular}{l|l|l|l|l|l}
\hline CONSULTING FIRM & A & B & C & D & E \\
\hline Effective & 165 & 240 & 85 & 355 & 370 \\
Neutral & 383 & 94 & 240 & 118 & 84 \\
Ineffective & 146 & 168 & 177 & 77 & 6 \\
Not Applicable & 42 & 56 & 94 & 97 & 22 \\
Not in Place & 0 & 0 & 44 & 5 & 36 \\
\hline
\end{tabular}

Table 3: ANOVA Summary on Risk Management

\begin{tabular}{llllcll}
\hline Source of Variation & $S S$ & $d f$ & $M S$ & $F_{\text {cal }}$ & P-value & F crit \\
\hline Between Groups & 5824.96 & 4 & 1456.24 & 0.093474 & 0.983408 & 2.866081 \\
Within Groups & 311582.40 & 20 & 15579.12 & & & \\
\hline Total & 317407.40 & 24 & & & & \\
\hline
\end{tabular}

Reject $H_{0}: F_{c a l}>F_{\text {tab }}$ i.e. if F- value $\left(F_{c a l}\right)>\mathrm{F}$ crit at $5 \%$; Since, $F_{\text {cal }}=0.093474<\mathrm{F}_{\text {crit }}=2.866081$, we accept $\mathrm{H}_{0}$ : The implication of accepting $\mathrm{H}_{\mathrm{o}}$ is that most home-based consulting engineers/project managers do not implement risk management processes religiously on projects.

\begin{tabular}{llllll}
\multicolumn{1}{c}{ Table 4: Weighted Response Data on Risk Identification } \\
\hline CONSULTING FIRM & A & B & C & D & E \\
\hline Strongly Disagree & 0 & 0 & 0 & 0 & 1 \\
Disagree & 0 & 0 & 10 & 0 & 0 \\
Neutral & 12 & 0 & 12 & 3 & 3 \\
Agree & 20 & 28 & 0 & 24 & 16 \\
Strongly Agree & 0 & 0 & 5 & 5 & 0 \\
\hline
\end{tabular}

Table 5: ANOVA Summary on Risk Identification

\begin{tabular}{lllllll}
\hline Source of Variation & $S S$ & $d f$ & $M S$ & $F_{\text {cal }}$ & P-value & F crit \\
\hline Between Groups & 19.36 & 4 & 4.84 & 0.057592 & 0.993339 & 2.866081 \\
Within Groups & 1680.8 & 20 & 84.04 & & & \\
Total & 1700.16 & 24 & & & & \\
\hline
\end{tabular}

Ajibola, OOE; Omiyale, AD; Ogunwolu, L 
Analysis of Data on Risk Identification: Reject $H_{0}: F_{c a l}>F_{\text {tab }}$ at $5 \% ; F_{c a l}=0.057592<\mathrm{F}_{\text {crit }}=2.866081$. Since F-value $\left[F_{c a l}\right]<F_{c r i t}$, then $\mathrm{H}_{\mathrm{o}}$ is accepted. The implication of this is that most home-based consulting engineers / project managers do not identify risk proactively on projects at optimal levels of the generally prescribed industry risk management standards holds.

Risk Management Analysis/Evaluation by home-based Consulting Engineers: Similarly, a second hypothesis was formulated and tested on risk management analysis or evaluation among home-based Engineering Consultants.

Table 6: Weighted Response Data on Risk Analysis

\begin{tabular}{llllll}
\hline CONSULTING FIRM & A & B & C & D & E \\
\hline Strongly Disagree & 0 & $\mathbf{0}$ & 0 & 0 & 1 \\
Disagree & 16 & 14 & 0 & 8 & 0 \\
Neutral & 36 & 39 & 108 & 27 & 24 \\
Agree & 60 & 4 & 20 & 92 & 60 \\
Strongly Agree & 15 & 0 & 0 & 5 & 20 \\
\hline
\end{tabular}

Table 7: ANOVA Summary on Risk Evaluation

\begin{tabular}{llllcll}
\hline Source of Variation & $S S$ & $d f$ & $M S$ & $F_{\text {cal }}$ & P-value & F crit \\
\hline Between Groups & 786.16 & 4 & 196.54 & 0.194683 & 0.938298 & 2.866081 \\
Within Groups & 20190.8 & 20 & 1009.54 & & & \\
Total & 20976.96 & 24 & & & & \\
\hline
\end{tabular}

Reject $H_{0}: F_{c a l}>F_{\text {tab }}$ at $5 \% ; F_{c a l}=0.194683<\mathrm{F}_{\text {crit }}=2.866081$. Since $F_{c a l}<F_{c r i t}$, we accept $\mathrm{H}_{0}$. The implication of this is that projects are not analyzed and evaluated proactively with respect to the generally prescribed industry risk management standards by home-based consulting engineers/ project managers.

Correlation between Management Approach and Risk Policy Implementation: Finally, the last hypothesis formulated and tested was on possible correlation between Risk Management Approach and its Policy Implementation amidst home-based Consulting Engineers. The hypothesis states thus:

Table 8: Correlation Coefficient for Risk Management Approach versus Risk Management Policy Implementation

\begin{tabular}{l|ll}
\hline & $X$ & $Y$ \\
\hline X ( Risk Management Approach) & 1 & \\
Y (Risk Management Policy Implementation) & 0.501642 & 1 \\
\hline
\end{tabular}

Since the correlation coefficient is 0.501642 , the $H_{0}$ (null) hypothesis is accepted. This implies that there is a positive correlation between risk mangement approach and management policy implementation on project success. Therefore, risk management approach is a function of mangement policy implementation.

Figure 1 shows the graphical relationship of the responses obtained on Risk management approach in relation with risk management implementation

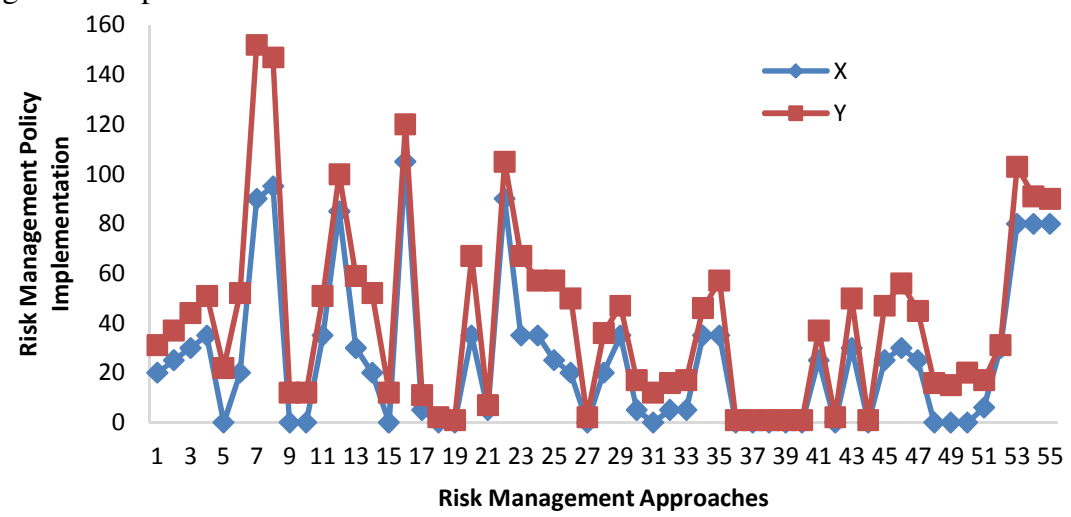

Fig 1: Risk management approach versus risk management implementation

The control of potential, hazards, threats, and vulnerabilities that could negatively affect project schedule is the basis for sound and successful risk management. Risks must be identified and described in an understandable way before they can be analysed and managed properly. Effective risk management includes early and aggressive risk identification through the collaborative efforts of relevant

Ajibola, OOE; Omiyale, AD; Ogunwolu, L 
stakeholders. Identifying and understanding risk therefore is an integral part of the risk management process.

The study also showed that there is a positive correlation between risk management approach and risk management policy implementation on project success. Therefore, it can be concluded that risk management approach is a function of risk mangement policy implementation.

Conclusion: This study has amply demonstrated that the home-based Engineers in Nigeria little appreciates the enormous potential contributions of risk assessment and management in the implementation of engineering projects. Project management experts in the country have attributed policy instability, faulty construction methodology, poor town planning approval, non-compliance with specifications/standards by developers/contractors, and poor legal framework to the cause of failure of projects in Nigeria. However, beyond these claims, the result of this research work has shown that poor risk management policy awareness and implementation are chief among the causes of project failure in Nigeria.

\section{REFERENCES}

Akintoye, A; Macleod J (1997). Risk analysis and management in construction. Int. J. Proj. Manag. 15(1): 31-38.

Aghili, S (2010). Organizational risk management. The Internal Auditor, 67(3): 21-23.

Al-Bahar; Jamal, F; Keith, C; Crandall KC (1990). Systematic risk management approach for construction projects, J. Const. Eng. Manage. 116(3), 533-546.

Aven, $T$ (2003). Risk analysis and management: Basic concepts and principles. $R \& R A T A$ 1(12) Volume 2.

Aven T (2010). Misconceptions of risk. Chichester, UK: John Wiley \& Sons.

Baker, S; Ponniah, D; Smith, S (1999). Survey of Risk Management in Major U.K. companies. J. Prof. Issues Eng. Educ. Pract. 125(3), 94-102.

BS IEC 62198:2001 Project risk management: Application. Guidelines, British Standard Institute, London.

Californian Department of Transport (2007). Caltrans project management handbook. Caltrans Office of Project Management Process Improvement $1120 \mathrm{~N}$ street, mail station 28 Sacramento, CA 95814, USA

Carter, R L and Doherty, N (1974). Handbook of Risk Management. Kluwer-Harrap, London, UK

Ajibola, OOE; Omiyale, AD; Ogunwolu, $L$
Crotty, M (1998). The foundations of social research. SAGE Publ. Ltd, London, UK.

Eugenijus, G (2006). The concept of risk and responsible conduct of research. J. Sci. Eng. Ethics 12 (1):75-83.

Fagbenle, OI; Oluwunmi, AO (2010). Building failure and collapse in Nigeria: the influence of the informal sector. J. Sus. Dev. 3(4): $268-276$

Flanagan, R; Norman G (1997). Risk management and construction. Blackwell Sci Publ, Oxford, UK.

Folagbade, SO (2002). Case studies of building collapse in Nigeria. Proceedings on building collapse: causes, prevention and remedies, Ondo State, Nigeria: The Nigerian Inst of Building, pp. 110-121.

Ibiwoye, A; Ajibola, OOE; Sogunro, AB (2012). Artificial Neural Network Model for Predicting Insurance Insolvency. Int. J. Manag. Bus. Res., 2 (1), 59- 68.

Oloyede, SA; Omoogun, CB; Akinjare, OA (2010). Tackling causes of frequent building collapse in Nigeria. J. Sus. Dev. 14: 127-132.

Omiyale, AD (2014). Risk management analysis for consulting engineers. M.Sc. dissertation. University of Lagos, Lagos, Nigeria.

Osipova, E (2008). Risk management in construction projects: a comparative study of the different procurement options in Sweden. Blackwell Pub, Oxford, UK.

Project Management Institute, (2004). A guide to project management body of knowledge fourth edition. Newtown Square, PA 19073-3299, USA.

RAMP (Institute of civil engineers and institute of actuaries) (1998). Risk analysis and management for projects, Thomas Telford, London, UK.

Shamoo, AE; Resnik, DB (2003). Responsible conduct of research. New York: Oxford University Press, UK.

Shehu, Z; Sommerville, J (2006). Real time risk management approach to construction projects. 6th Inter. Postgraduate Research Conference (IPRC). Sri Lanka.

Smith. NJ; Merna, T; Jobbling P (2006). Managing risk in construction projects. 2nd

Edition Oxford: Blackwell Publishing

Thompson P; Perry JG (1992). Engineering construction risks: a guide to project risk analysis and assessment implications for project clients and project managers. Thomas Telford Publishing, Thomas Telford Ltd, 1 Heron Quay, London, UK. 